\title{
The effect of product colour and odour on consumers' perceived preference and intensity ratings
}

\author{
Adriana Starostová \\ University of Economics \\ Prague, Czech Republic \\ adriana.starostova@vse.cr.
}

\section{Pavel Zimmermann}

University of Economics

Prague, Czech Republic

zimmerp@vse.cz.

\author{
Václav Stř́iteský \\ University of Economics \\ Prague, Czech Republic \\ stritesı@vse.cr.
}

Abstract. Due to high competitiveness, product innovation requirements and customer demand, the importance of the field of sensory marketing has increased. The term refers to the characteristics of products, things or even services that might impact our further sensory input and trigger human senses. This study presents the results of an experiment designed to test the effect of 16 colour and scent combinations (representing visual and olfactory modalities) on perceived preference and intensity. The research aims to investigate whether the same scent can be rated differently in variously coloured packaging and therefore affect consumers' perception and evaluations. A total of 301 students have taken a part in this experiment. The colours used in this experiment were green, yellow, orange and purple. The scents were selected to correspond to the widely commercially used odour/ colour combinations in the FMCG sector in the Czech Republic. The results suggest that colour played a significant role in consumers' preference ratings when evaluating the same scent and therefore colour has the ability to affect the perception of odour. However, colour did not have any effect on perceived intensity ratings. Linear regression analysis suggests that semantic associations as used in FMCG sector for colour-odour congruency does not fit the data and hence, the model for prediction of preference ratings is probably far more complicated.

Keywords: Sensory Marketing, cross-modal correspondences, consumer behaviour, 
consumer preference, scent intensity, Czech Republic.

JEL Classification: M31, M39

\section{INTRODUCTION}

In order to understand a customer in a more thorough manner, it is crucial to realise that more than $90 \%$ of all information are being processed on the subconscious level in the brain (Zurawicki, 2010). All the five senses - taste, touch, olfaction, hearing and vision are the main and basic tool of perception. More importantly, a company does not have a choice to provide no sensory aspects because they are always present. However, a company can pre-select those attributes or choose to ignore them. The reason to research the field more is that there is an entirely new wave of managers who are paying more attention to the role of sensory aspects and experiential factors when designing new marketing strategies (Wirley-Birch, 2013) due to mounting pressure on improving market share. Corporations tend to invest substantial amounts to new ways of maintaining or enhancing profits. A key role in this process is assigned to product innovation, unique ways of product sale and one of the greatest remaining challenges, i.e. to attract, satisfy and sustain costumers. Sensory marketing might serve as a tool to convey the correct message about a product, it might potentially enhance the products characteristics, but also potentially mislead the customers. Krishna (2012, p.332) defines the term as "Marketing that engages the consumers' senses and affects their perception, judgment and behaviour". Together with the advancement of new technologies, i.e. virtual reality, these tendencies will be probably increasing and the consumers will demand more sophisticated forms of communication and presentation of individual products.

It appears valid to emphasise the importance of more research through noting that there are already some commercial laboratories that are exploring the possibility of designing universal tools able to transfer the olfactive experience (for instance Nakamoto laboratory or Sensonics International). This would open a completely new dimension of internet commerce where the users would be able to smell the product when online while actually not leaving home. There are also some mobile phone applications in development (i.e. oPhone) which are yet awaiting mass-production but appear to some extent to be functional (Nelson, 2014). However, most of the tools have not yet reached commercial success due to the limited amounts of scents they are able to transmit to the user (Carulli et al., 2015).

Should there exist such a solution, would the use of certain colours of packaging impact perceived odour preference and intensity ratings? The aim of the paper is to examine how different colour-odour combinations affect intensity and preference ratings. A simple association model is applied in order to examine the impact of congruency between colour and odour on preference and intensity ratings (how lemon scent and yellow colour vs lemon scent and other colours affect perceived preference and intensity). The marketers, product designers and product managers might find the results beneficial for their decision-making as in practice, the choice of product odour and colour is largely based on intuition. In order to answer all the questions, it is important to first outline the previous research of cross-modal correspondences and summarise previous findings related to colour and odour.

\section{LITERATURE REVIEW}

\subsection{Cross-modal correspondences}

There is an extensive number of researchers that dedicated years to the investigation of sensation transference (Aradhna Krishna, Charles Spence), meaning that one sense has the ability to impact other sense and affect the sensation. Moreover, there is a term cross-modal correspondence, which is similar - 
it means that there are certain patterns in human brain which can be commonly found and somehow correspond with each other related specifically to modalities, in this case vision and olfaction. These revelations are known for many years and one of the foremost examples is McGurk's effect (1976) where the visual and auditory perception together create a multisensory illusion. The cross-modal correspondences have been proven to exist between various sensory modalities, such as between vision and touch; audition and touch or tastes and sounds (see Spence, 2011 for full review). However, there are very few articles dedicated to cross-modal correspondences between olfaction and vision, specifically in relation to colour and odour perception (see Gilbert et al., 1996; Spence, 2010).

The psychologists have known about cross-modal correspondences for many years (see, for example, Jespersen, 1922; Köhler, 1929; Sapir, 1929; Newman, 1933; Fox, 1935; Wertheimer, 1958), but used various terms to describe it such as cross-modal associations. The term cross-modal correspondence used in this study refers to a compatibility effect between attributes or dimensions of a stimulus (i.e., an object or event) in different sensory modalities (be they redundant or not) as defined by Spence (2011).

In contrast, there is also some early research by Marks (1978) that places the existence of colour and odour cross-modal correspondences in question by saying: "Whereas coloured hearing synaesthesia is dominated by regular and systematic correlations between visual and auditory dimensions of sensory experience, other forms of synaesthesia are generally much more erratic and idiosyncratic, in that they rarely reveal common patterns or dimensions ( $p$. 98-99)". Moreover, Ehrlichman \& Bastone (1992) argued that widely held view is that odour associations, preferences, and memories originate from idiosyncratic personal experience. Despite the conflicting opinions, this claim has been already contradicted by Gilbert et al., 1996 who showed the evidence that colour-odour correspondences exist and show a similar degree of consistency over time. Although Gilbert et al. (1996) confirmed the existence, they have not confirmed any effect of congruent colour and odour on perceived intensity and preference ratings, since their participants only had to select one coloured chip when smelling an odour without providing additional information.

The oldest studies of smell can be traced back to psychology and fundamental sciences. It has been shown that colour cues can bias odour judgments (Engen, 1972; Zellner \& Kautz, 1990). In the first case, Engen (1972) found that adding colour increases the inaccuracy of odour recognition. In the second case, the authors found that coloured solutions were rated as more intensive than the transparent ones.

Moreover, there is evidence that the appropriateness of the colour-odour pairing determines whether the bias aids or impairs performance (Burghardt, 1977; Davis, 1981; Zellner et al., 1991). Appropriate colours increase and inappropriate colours reduce the accuracy of odour identification. These findings suggest that there might exist such correct associations of colours for odours and it might help the consumer to recognise the given scent.

\subsection{Research findings about olfaction with application to marketing}

More recent research suggests that the sense of smell is critical to the perception of flavours; can affect our mood, promote products or position a brand (Herz, 2007; Morrin, 2010). Previous research also indicates that although sometimes it is hard to measure, experiential marketing enhances the positive experience by the added value provided to the consumer (Babin et al., 1994; Holbrook, 1999) and increases the potential for building loyalty (Pine \& Gilmore, 1998; Gobé, 2001) and sensory marketing is sometimes perceived as one aspect of experiential marketing (Schmidt, 1999), rather than a particular field. Many papers have been published about odour recognition (Lawless \& Engen, 1977; de Wijk, Schab \& Cain, 1995; Schab \& Crowder, 1995) and its impact on memory. More specifically, Herz (2007) concluded that memories associated with scent retrieval cues were regarded as more emotional than those evoked by the other types. Soars (2009) similarly states that the sense of smell has the highest emotional connection 
which sends a fast signal to the limbic system and connects emotions to memory. Therefore, the transfer of olfactory information differs from that of the other senses. It could be summarised that it has a more direct link with feelings, which makes scent marketing a powerful tool for marketers. According to Schacter and Tulving (1990), explicit memory creates our perception of the external world. On the other hand, there is also implicit memory that is restricted to learn responses to stimuli. When someone is asked to remember an odour, he is unable to re-access the stimuli from the implicit memory. However, once the scent is smelled, it will activate concepts in explicit memory and recall connected memories and associations with particular odours.

This is essentially why previous work identified that humans often experience problems when assigning verbal attributes to scents (Lawless \& Engen, 1977; de Wijk et al., 1995). However, the human memory can preserve extensive information about them (Crowder \& Schab, 1995). An interesting study conducted by Engen et al. (1973) showed that the recognition of various scents lasts longer compared to visual stimulants. Ebbinghaus (1913) claimed that the memories gathered by other senses than smell tend to disappear quicker. More recently, Chu and Downes (2002) discovered that autobiographical information gathered by olfaction is more detailed, followed by Willander and Larsson (2006) who described this information as obsolete. Other researchers found (Krishna, Lwin \& Morrin, 2010) that scent enhances recall of verbal information presented with the product. Furthermore, it has been documented that pleasant scents can enhance the customer experience and also favourably influence store evaluations (Laird, 1932; Spangenberg et al., 1996 Bosmans, 2006), encouraging a visit to the store or affect the decision to return to it (Bone \& Ellen, 1999).

\subsection{The effect of colour and odour on human behaviour}

According to Hultén et al. (2009), sensory marketing, and therefore also singular aspects such as colour and odour, can contribute to an individual's final purchase as well as consumption experience. Despite this, few studies that focused on the effect of scented environment showed mixed results. Knasko et al. (1990) found that customers stayed longer in the store with fragrance presence, but this did not impair their purchase intentions. It was argued that the settings of the experiments were within a jewellery store and therefore the expenditure would have to be relatively high. Hirsch (1995) conducted the same research within a casino and results showed that players stayed longer and consequently spend more when the fragrance was present in the environment. This might show that if there are primarily other motives to purchase (or not to purchase) a product - such as its functionality or cost, sensory attributes cannot influence this. However, it might facilitate longer exposure or increase expenses once the decision has been already made. Several other studies suggest that ambient scent in the environment can elicit emotional responses that can influence product and store evaluations (Bitner 1992; Gulas \& Bloch, 1995; Zeithaml \& Bitner 2000; Gorn, Pham, \& Sin 2001; Bosmans, 2006).

Despite relatively many studies on scent in the store environment, the ones concerning product scent are relatively scarce. Gatti et al. (2012) examined the effect of product's weight (in this case a liquid bath soap), colour and different perfume concentrations on perceived intensity and efficacy. The perceived intensity was significantly enhanced when the soap was coloured. The perceived efficacy was also enhanced when the soap weighted more.

There are many early studies on the effect of colour on food, such as the one by Gormley (1992) who found that consumers regardless of their ethnicity or sex prefer more orange colour of salmon. In contrary, more recent study by Carpenter et al. (2001) shown that colour or packaging did not affect taste scores. Research into food liking among children has shown the importance of colour as a variable (Leon et al., 1999). Marshall et al. (2006) investigated this further and the results showed a high correlation 
between favourite colour and choice of product across the total sample of pre-school children. They were also able to identify the most popular colour choices. Moreover, Piqueras-Fiszman and Spence (2012) shown that the colour of packaging has an effect on consumption experience.

Last, but not least, the effect of colour preference on purchase decisions was studied by $\mathrm{Yu}$ et al. (2018) who found that personal colour preferences affect intended product-colour purchase decisions but that the extent of this varies from one product category to the next and moreover that personal colour preferences are secondary to colour functionality and colour performance.

The literature review illustrates that there is a growing body of research on the topic of cross-modal correspondences and sensory marketing. However, up to date and to the best knowledge of the author, there is no evidence showing the effect of a combination of product colour and odour on consumer preference ratings. The motive behind the study is to suggest the best approach to marketers on how to select the best matching odour and colour pairings and expand the theories of possible congruency. Furthermore, the key factors that might play a role in preference ratings when evaluating a combination of colour and odour will be identified.

\section{METHODOLOGY}

\subsection{Participants}

In total 301 participants, mostly students between 18 to 24 years agreed to voluntarily participate in an experiment conducted at the University of Economics in Prague. The final sample contained 130 males and 167 females after clearing the data set from the participants who left the columns blank (4 participants). The respondents were tested for their ability to recognise the colours used in the experiment and tested for their ability to smell. The final data set was also cleared from the participants who did not answer the screening questions correctly. The sample size appeared to be adequate since every participant had to rate the preference of 4 colour and odour combinations which were distributed randomly, but equally to the respondents. The experiment is in accordance with the ethics of University of Economics in Prague.

\subsection{Stimuli}

The participants were given 4 differently coloured fragrance bottles, all of which had the same shape (Fig. 1). The fragrance bottles contained each $2 \mathrm{ml}$ of one out of 4 possible types of fragrances which was equally distributed. In addition, each participant obtained one transparent fragrance bottle with 2 possible options of fragrance based on their group. The transparent bottles contained $2 \mathrm{ml}$ of testing sample fragrance - either cinnamon oil solution or vinegar has been selected to test the participants for anosmia (either temporal or permanent loss of the sense of smell). All the fragrances had the same concentration level and the liquids were naturally transparent in colour, except for cinnamon oil solution and vinegar anosmia testing samples. Those were naturally yellow in colour. The 4 possible colours of the fragrance bottles were purple, orange, yellow and green. The scents were selected to correspond to the mostly used colour and odour combinations in the FMCG sector (Fast-moving consumer goods) in the Czech Republic. Hence, the 4 scents chosen were lemon (yellow), orange (orange), grass (green) and lavender (purple). Table 1 shows the possible combinations (group A-H) of colour and odour distributed across the participants. 
An overview of the distribution of colour and odour combinations

\begin{tabular}{|c|c|c|c|c|c|}
\hline Group & Fragrance bottle & Fragrance bottle & Fragrance bottle & Fragrance bottle & Anosmia test sample \\
\hline A & A1 & B3 & C4 & D2 & Vinegar \\
\hline B & A1 & B3 & C4 & D2 & Cinnamon \\
\hline C & A4 & B2 & C1 & D3 & Vinegar \\
\hline D & A4 & B2 & C1 & D3 & Cinnamon \\
\hline E & A2 & B4 & C3 & D1 & Vinegar \\
\hline F & A2 & B4 & C3 & D1 & Cinnamon \\
\hline G & A3 & B1 & C2 & D4 & Vinegar \\
\hline H & A3 & B1 & C2 & D4 & Cinnamon \\
\hline
\end{tabular}

Scent: 1 = Grass; 2 = Orange; 3 = Lemon; 4 = Lavender Colour: A =Green; B = Orange; C = Yellow; D = Purple

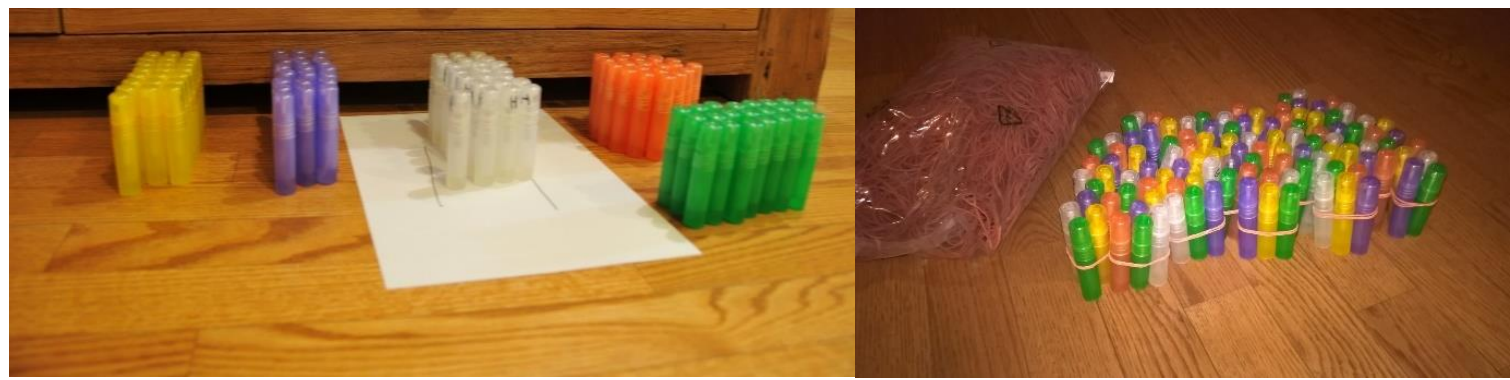

Figure 1. Fragrance bottles

\subsection{Ishihara colour blindness test, anosmia test and the procedure of sampling}

All the participants were tested for colour blindness (Ishihara colour blindness test, 1972 - a screening method for colour recognition) and anosmia test a prior to the experiment. The participants were shown pictures (see Fig. 2) which were pre-selected with an emphasis on the deficiency of colours used in the experiment. The participants had to answer correctly what number they see on the pictures. Only the participants with two answers answered correctly were included in the data analysis. Moreover, the participants had to smell one out of two possible scents - either vinegar or cinnamon oil solution and note the correct answer. Unfortunately, this method also excluded the participants who noted less exact and more emotional answer from the experiment (i.e. "Christmas baking" for cinnamon oil solution or "Cleaning" for vinegar). The test for anosmia was conducted in accordance with the standard ISO/IEC 8589: "Sensory analysis - General guidance for the design of test rooms". The participants were requested to spray (through an applicator) the solutions twice on the provided white perfume testing stripes. They also obtained coffee beans and were instructed to smell them in between the ratings in order to disrupt the scent from the previous sample.

\subsection{Colour and odour characteristics}

The fragrance types were selected after a preliminary research and interviews with the local perfumers. Their general recommendation was to use more natural scents originating from France, since they are more likely to contain the original essences of true lemon fruit, lavender, orange and grass due to 
perfume industry standards. After sampling many perfume samples and careful integration about its content, we selected fragrances from a manufacturer "Provence and the nature". The fragrances did not vary in concentration. All 4 fragrance types were transparent in colour. Two fragrances used for anosmia test were selected to be most common, i.e. easily recognised by most people. Moreover, affordability of such solutions also played a role. Regularly sold vinegar was used as first anosmia test. For the second option of the test, cinnamon oil solution has been made from cinnamon oil, denatured alcohol $(96 \%)$ and distilled water.
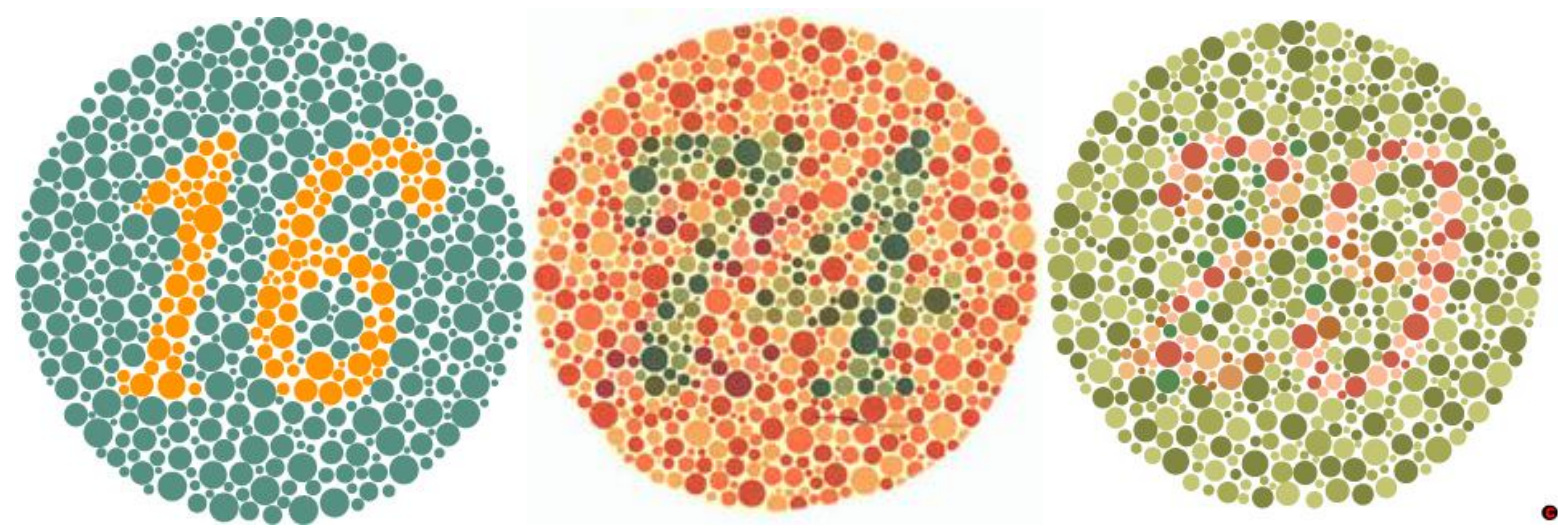

Figure 2. Ishihara Colour Blindness Test - The exact pictures used in the experiment

\subsection{Task and experiment procedure}

The participants received a questionnaire where they had clear instructions on how to manipulate with the fragrances. A prior to the experiment, they filled a written consent with an anonymous participation in an experiment and stated any known allergies. First, they had to fill questions about gender, age group, self-assigned cultural belonging, their preferred colour (out of 4 options) and whether they have lived in another country for more than 5 years. Once they answered both tests (anosmia and colour blindness), they could continue towards sampling the fragrances. Each participant was assigned one of the groups (A-H) to sample and had to evaluate the fragrance a) intensity and b) preference on a scale from 1 to 10 .

\section{EMPIRICAL RESULTS AND DISCUSSION}

\subsection{Statistical methods and collected data}

After clearing the questionnaires from the ones which were left blank (4), other 33 respondents were excluded from the analysis due to the fact that they did not pass the colour blindness test or the anosmia test. Remaining 264 respondents were included in our statistical analysis. Each respondent tested four fragrances so altogether we analysed 1056 observations. Preference and intensity rankings were assessed as a numerical variable. Equidistance of scale points is assumed. Besides the rankings, data also contained records of cultural belonging, nationality, age group, gender and preferred colour.

We made two main simplifying assumptions. For ANOVA and linear regression, we assumed that both scales are normally distributed and that observations are independent and have identical variance in each group considered. As the scales are in fact discrete on the range 1-10 and four observations are collected for each respondent, these assumptions are not fully valid in our experiment. Tails are heavier 
than normal. Therefore, statistical significance is interpreted with this limitation and focus is put on descriptive outputs of the statistical tools applied.

Standard univariate and two-variate exploratory analysis was applied and difference in group means was studied in order to reveal the standard relation between the preference and intensity ratings of different fragrances and bottle colours. Statistical significance of the differences was then tested using two-way ANOVA. All analyses were performed in statistical software R ${ }^{1}$.

\subsection{Results}

\subsubsection{Dependence of fragrance preference}

The univariate analysis of fragrance preference was applied first. Mean preference of different fragrances is displayed on Figure 3 with the dashed lines. Lavender was overall the least preferred scent, followed by orange, lemon and grass. Difference between lemon and grass is relatively marginal. Two-way analysis of the dependence of the preference on the fragrance type and bottle colour simultaneously provides better insight in the dependence structure (Tab. 2). Bars on Figure 3 display mean rate of preference by fragrance type and bottle colour. The colours of the bars correspond with the bottle colour. For the preference rate, it is clear that there was a difference observed for different fragrances as well as for different bottle colours for each fragrance. The mean for lavender was 4.85 , while as for grass was 6.87. Different height of each quartet of bars corresponds with the conclusion of the univariate analysis that the preference of fragrance depends on its type. This analysis further reveals that bottle colour has different impact on preference for different fragrance types. We can see that sensitivity of preference of the fragrance on the bottle colour is much higher for lavender or lemon than for orange or grass. Twoway ANOVA test (Tab. 2) confirms statistical significance of simultaneous dependence of fragrance preference on both fragrance type and bottle colour. Corresponding interaction displays also a significant impact (at $10 \%$ significance level). This suggests that certain difference in preference occurs for certain combinations. This result is analysed further in Section 4.2.2 with the regression model.

Table 2

Two-way ANOVA test results for preference

\begin{tabular}{|c|c|c|c|c|c|}
\hline & Df & Sum Sq & Mean Sq & F value & $\operatorname{Pr}(>\mathbf{F})$ \\
\hline Fragrance & 3 & 669 & 223.11 & 37.277 & 0.000 \\
\hline Colour & 3 & 79 & 26.47 & 4.423 & 0.004 \\
\hline Interaction & 9 & 98 & 10.9 & 1.822 & 0.060 \\
\hline
\end{tabular}

\subsubsection{Dependence of fragrance intensity}

Figure 4 displays mean rate of intensity by fragrance type and bottle colour. Black dashed lines again represent mean intensity for each fragrance. The univariate analysis of fragrance intensity was performed. Lavender was generally least intense fragrance, followed by orange, lemon and grass, which is the same ordering as we observed for fragrance preference. Difference in mean fragrance intensities is much lower than for mean fragrance preference. The mean for lavender was 6.1, while as for grass was 7.02. Two-way ANOVA (Tab. 3), however suggests statistically significant impact of the fragrance type on intensity.

${ }^{1}$ Available to download: https://www.r-project.org/ (OThe R Foundation, 2018) 
Although certain differences in intensity for different colours are observable, the magnitude of the differences is rather low.

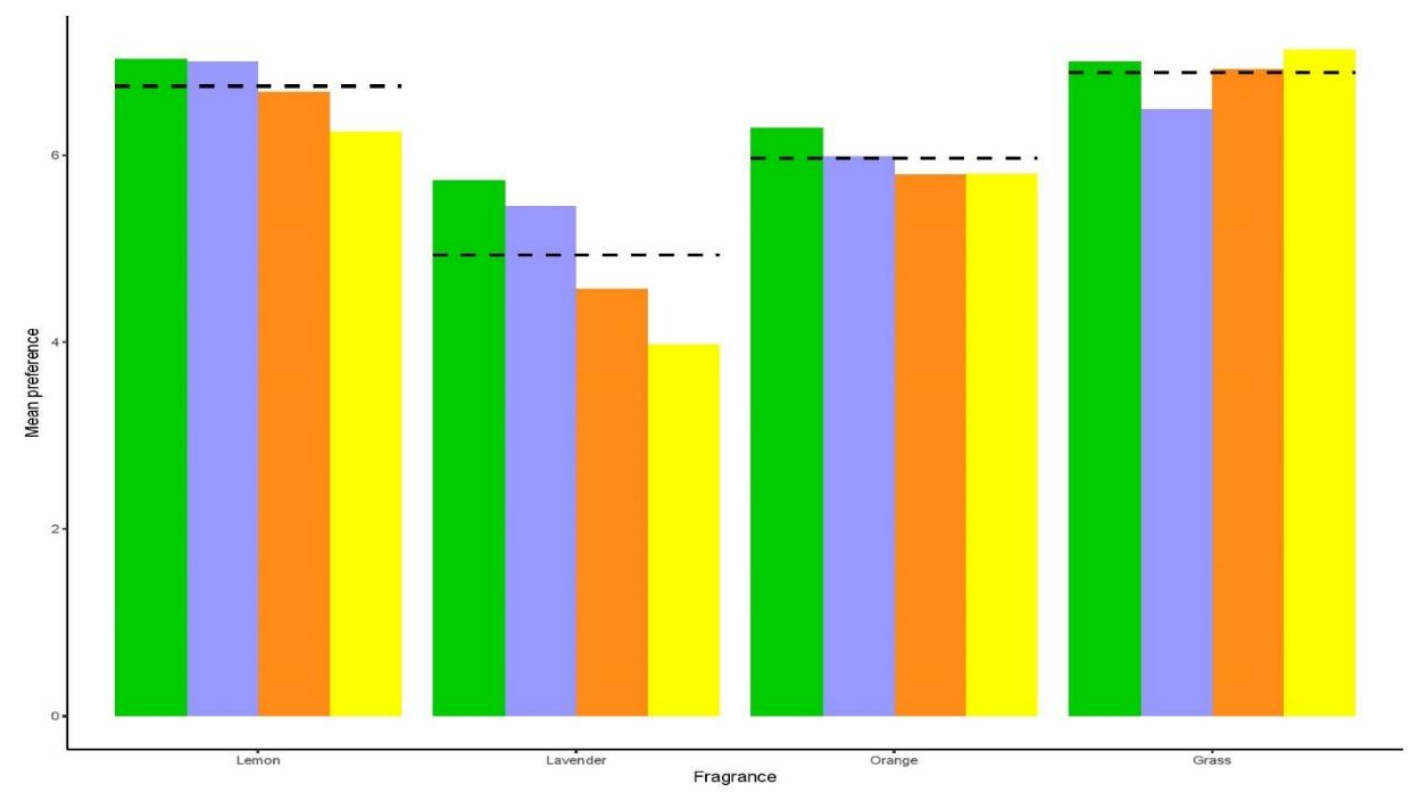

Figure 3. Mean rates of preference

Table 3

Two-way ANOVA test results for intensity

\begin{tabular}{|c|c|c|c|c|c|}
\hline & Df & Sum Sq & Mean Sq & F value & $\operatorname{Pr}(>\mathbf{F})$ \\
\hline Fragrance & 3 & 120 & 40.12 & 8.400 & 0.000 \\
\hline Colour & 3 & 19 & 6.43 & 1.345 & 0.258 \\
\hline Interaction & 9 & 36 & 4.01 & 0.840 & 0.579 \\
\hline
\end{tabular}

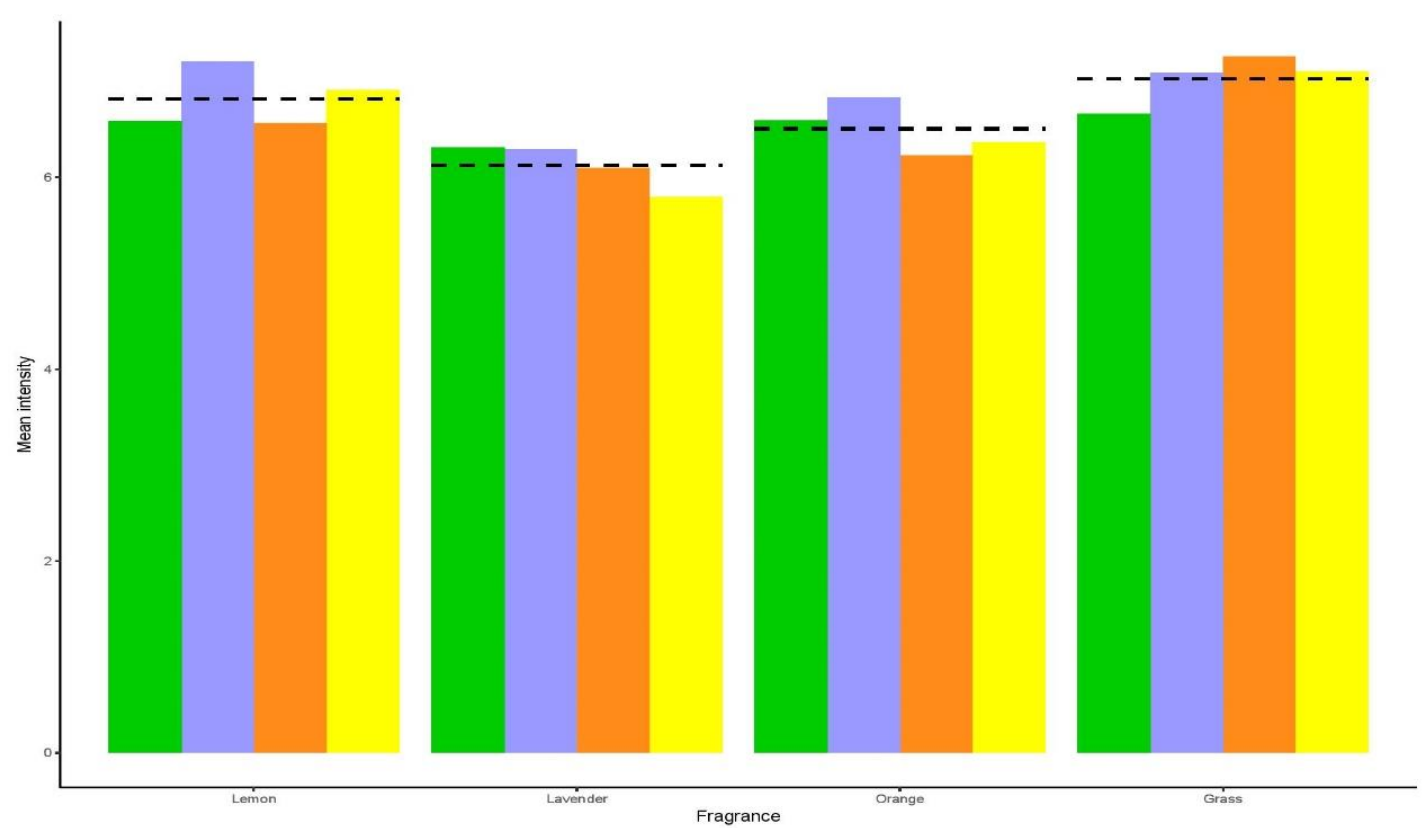

Figure 4. Mean rates of intensity 


\subsubsection{The effect of congruent colour on the perception of odour}

In order to reveal more details about the dependence structure of fragrance preference, a multivariate analysis was performed using the classical linear model. The effect of the fragrance preference was explained by:

1) control variates: cultural belonging (CZE and other), age group (young and other), gender and preferred colour (4 levels),

2) bottle colour (4 levels),

3) and fragrance type (4 levels).

4) Furthermore the significant interactions were added (see the estimates in Tab. 4 for description).

As all these variables are categorical, dummy variables were created for each level (except for reference levels). More details on our model specification are in the Appendix. Only orange preferred colour displayed significant difference so the levels of the variable preferred colour were merged to only Orange and Other colour.

The congruency was at first assessed by analysing the most popular matches of colour and odour on the Czech market within FMCG sector (Fast-moving consumer goods). Furthermore we analysed significance of colour odour pairwise-interactions. The most important colour and odour combinations regularly sold within stores in Czech Republic had the following colour and odour combinations: purple and lavender scent, orange and orange as a fruit, yellow and lemon scent and green and grass. These combinations are often intuitively selected in order to brand and design products as they also represent the classic semantic associations. We created an indicator variable, referred to as Semantic associations, indicating presence of these combinations for each observation. Significance of this variable was rather low $(p$-value $=0.577)$ and more over the parameter estimate was negative $(-0.109)$. Therefore, the results do not support the hypothesis that the market standard colour-fragrance combinations increase the fragrance preference.

The above mentioned results of the two-way analysis of variance (Tab. 2), however, suggest that certain colour-odour interaction exists. Therefore, interaction of bottle colour and fragrance type levels were added in the model. Not all 16 combinations of bottle colour and fragrance type levels show a large effect additional to the main effect. The most significant interactions were (see the estimates in Tab. 4 in the Appendix):

- I1...The interaction between orange bottle colour and lavender fragrance which decreased the preference.

- I2...Interaction of yellow bottle and lavender which decreased the preference.

- I3...Interaction of yellow bottle and grass fragrance which increased the preference.

In other words, some colour-odour interactions do make a difference in the consumer preference and intensity perception, while others do not. Nonetheless, the interactions which do and do not make a difference for the consumer cannot be explained only by the simple formed assumptions about colour and odour combinations such as lemon fragrance being associated with yellow colour as applied in practice to brand and design products. 


\section{CONCLUSION}

Two-way ANOVA confirmed statistical significance of the simultaneous dependence of fragrance preference on both fragrance type and bottle colour. This might have potential implication for product designers, marketers and managers suggesting that more attention should be paid to colour and odour combinations when launching new products. However, the effect of colour on perceived intensity ratings has not been demonstrated and the results of Two-way ANOVA are not statistically significant. In summary, the effect of colour on the perception of odour has been identified and therefore the existence of cross-modal correspondences between colour and odour has been demonstrated.

Moreover, we wanted to examine the relationship between congruent colours based on mostly sold product colour-odour combinations which comply with semantic associations used predominantly in order to brand the products. Linear regression analysis was applied and the results suggest that the currently used combinations of colour-odour congruency does not fit the experimental data and therefore that a different model could improve the direct impact of branding on consumers and consequently increase the sales. Nonetheless, more research and analysis are required before the specifics of such a model can be identified.

Finally, interesting results might be obtained with regards to the role of colour preference, gender, culture and age through regression analysis which might serve as a basis for further research of the combined effects of consumer characteristics on preference level of colour and odour.

\section{ACKNOWLEDGEMENT}

This project was supported by the Internal Grant Agency of the University of Economics in Prague, project no. F3/26/2018 "Sensory marketing and multimodality of the senses: the effect of product colour on the odour preference". No funds have been assigned to publishing in open access. Moreover, the authors would like to thank to all the local perfumers for their invaluable advices and insight with regards to the research design.

\section{REFERENCES}

Babin, B.J., Darden W.R. \& Griffin, M. (1994). Work and/or Fun: Measuring Hedonic and Utilitarian Shopping Value. Journal of Consumer Research, 20 (4), 644-656.

Bitner, J.M. (1992). Servicescapes: The Impact of Physical Surroundings on Customers and Employees. Journal of Marketing, 56, 57-71.

Bone P.F. \& Scholder, E.P. (1999). Scents in the Marketplace: Explaining a Fraction of Olfaction. Journal of Retailing, 75 (2), 243-62.

Bosmans A. (2006). Scents and Sensibility: When Do (In)Congruent Ambient Scents Influence Product Evaluations?. Journal of Marketing, 70 (3), 32-43.

Burghardt, G. M. (1977). The ontogeny, evolution, and stimulus control of feeding in humans and reptiles. In M. R. Kare \& O. Mailer (Eds.). The chemical senses and nutrition (pp. 253-275). New York: Academic Press.

Carpenter, C., Cornforth, D. \& Whittier, D. (2001). Consumer preference for beef color and packaging affect eating satisfaction. Meat Science, 57, 359-363.

Carulli, M., Bordegoni, M. \& Cugini, U. (2016). Integrating Scents Simulation in Virtual Reality Multisensory Environment for Industrial Products Evaluation. Computer-Aided Design and Applications, 13(3), 320-328. doi: 10.1080/16864360.2015.1114390

Chu, S. \& Downes, J.J. (2002). Proust nose best: Odours are better cues of autobiographical memory. Memory and Cognition, 30 (4), 511-518.

Crowder, R. G., \& Schab, F. R. (1995). Imagery for odors. In R. G. Crowder \& F. R. Schab (Eds.). Memory for odors (93-107). Hillsdale, NJ: Erlbaum. 
Davis, R. G. (1981). The role of nonolfactory context cues in odor identification. Perception \& Psychophysics, 30, 83-89.

de Wijk R.A., Schab F.R. \& Cain W.S. (1995). Odor identification. In: Schab F.R., Crowder R.G., editors. Memory for odors. Mahwah, NJ: Lawrence Erlbaum Associates, Inc., Publishers; 21-37.

Ebbinghaus, H. (1913). Memory: A contribution to experimental psychology.

Ehrlichman, H., \& Bastone, L. (1992). Olfaction and emotion. In M.J. Serby \& K. L. Chobor (Eds.), Science of olfaction, 410-438. New York: Springer- Verlag.

Engen, T. (1972). The effect of expectation on judgments of odor. Acta Psycho- logica, 36, 450-458.

Engen T. \& Ross B.M. (1973). Long-term memory of odors with and without verbal descriptions. Journal of Experimental Psychology. 100(2), 221-227.

Fox, C. W. (1935). An experimental study of naming. The American Journal of Psychology, 47, 545-579.

Gatti, E., Bordegoni, M. \& Spence, Ch. (2014). Investigating the influence of color, weight, and fragrance intensity on the perception of liquid bath soap: An experimental study. Food Quality and Preference, 31, 56-64.

Gilbert, A. N., Martin, R. \& Kemp, S. E. (1996). Cross-modal correspondence between vision and olfaction: The color of smells. The American Journal of Psychology, 109, 335-351.

Gobé, M. (2001). Emotional branding: The new paradigm for connecting brands to people: Allworth Press.

Gormley, T. (1992). A Note on Consumer Preference of Smoked Salmon Colour. Irish Journal of Agricultural and Food Research, 31 (2), 199-202.

Gorn, G., Pham, M.T. \& Sin, L.Y. (2001). When arousal influences ad evaluation and valence does not (and vice versa). Journal of Consumer Psychology, 11, 43-55.

Gulas, C.S. \& Bloch, P.H. (1995). Journal of Business Psychology, 10, 87.

Herz, R.S. (2007) The scent of desire: Discovering our enigmatic sense of smell. New York: William Morrow/HarperCollins.

Hirsch, A. (1995). Effects of Ambient Odours on Slot-Machine Usage in a Las Vegas Casino, Psychology and Marketing, $12(7), 585-594$.

Holbrook, M.B. (1999). Consumer value: A framework for analysis and research. Routledge.

Hultén B. (2009). Sensory marketing: the multi-sensory brand-experience concept, European Business Review, 23 (3), 256-273.

Ishihara, S. (1917). Tests for colour blindness (1 $\left.{ }^{\text {st }} \mathrm{edt}\right)$. Tokyo, Kanehra Shuppan.

Jespersen, O. (1922). The symbolic value of the vowel i. Philologica, 1, 1-19.

Knasko, S. (1989). Ambient odour and shopping behaviour. Chemical Senses, 14 (5), 179.

Köhler, W. (1929). Gestalt psychology. New York: Liveright.

Krishna, A., Lwin M.O. \& Morrin, M.(2010). Product Scent and Memory, Journal of Consumer Research, 37 (1), 57-67.

Krishna, A. (2012). An integrative review of sensory marketing: Engaging the senses to affect perception, judgment and behavior. Journal of Consumer Psychology, 22(3), 332-351.

Laird D.A. (1932). How the Consumer Estimates Quality by Subconscious Sensory Impressions: With Special Reference to the Role of Smell, Journal of Applied Psychology, 16 (3), 241-46.

Lawless, H., \& Engen, T. (1977). Associations to odors: Interference, mnemonics, and verbal labeling. Journal of Experimental Psychology: Human Learning and Memory, 3(1), 52-59.

Léon, F., Couronne, T., Marcuz, M.C \& Köster, E. (1999). Measuring food liking in children: A comparison of nonverbal methods. Food Quality and Preference, 10, 93-100.

Marks, L. E. (1978). The unity of the senses: Interrelations among the modalities. New York: Academic Press.

Marshall, D., Stuart, M. \& Bell, R. (2006). Examining the relationship between product package colour and product selection in pre-schoolers, Food Quality and Preference, 17 (7-8), 615-21.

McGurk, H., \& Macdonald, J. (1976). Hearing lips and seeing voices. Nature, 264, 746-748.

Morrin, M. (2010). Scent marketing: An overview. In A. Krishna (Ed.), Sensory marketing: Research on the sensuality of products, pp. 75-86. New York: Routledge, Psychology Press.

Nelson, K. (2014). This App Can Send Scented Text Messages. Retrieved from: https://mashable.com/2014/06/17/ophone-scented-texts/\#fyoYeIVnoiqw.

Newman, S. S. (1933). Further experiments in phonetic symbolism. The American Journal of Psychology, 45, 53-75.

Pine, B.J. \& Gilmore, J.H. (1998). Welcome to the Experience Economy, Harvard Business Review, 97-100. 
Piqueras-Fiszman, B., \& Spence, C. (2012). The influence of the color of the cup on consumers' perception of a hot beverage. Journal of Sensory Studies, 27, 324-331.

Sapir, E. (1929). A study in phonetic symbolism. Journal of Experimental Psychology, 12, 225-239.

Schacter, D.L. \& Tulving, E. (1990). Priming and the human memory system. Science, 247, 301-306.

Soars, B. (2009). Driving sales through shoppers' sense of sound, sight, smell and touch, International Journal of Retail and Distribution Management, 37 (3), 286-298.

Spangenberg E.R., Crowley, A. E. \& P.W. Henderson (1996). Improving the Store Environment: Do Olfactory Cues Affect Evaluations and Behavior? Journal of Marketing. 60, 67-80.

Spence, Ch. (2010). The color of wine-Part 1. The World of Fine Wine, 28, 122-129.

Spence Ch. (2011). Cross modal correspondences: a tutorial review. Attention, Perception and Psychophysics, 73, $971-995$.

Wertheimer, M. (1958). The relation between the sound of a word and its meaning. The American Journal of Psychology, 71, 412-415.

Willander, J., \& Larsson, M. (2006). Smell your way back to childhood: Autobiographical odor memory. Psychonomic Bulletin \& Review, 13(2), 240-244.

Yu L., Westland S., Li Z., Pan Q., Shin M.J. \& Won S. (2018). The role of individual colour preferences in consumer purchase decisions. Color Research and application, 43, 258-267.

Zeithaml, V.A. \& Bitner, M.J. (2000). Service marketing: Integrating customer focus across the firm (2nd ed). New York: Irwin McGraw-Hill Publishing Company.

Zellner, D. A., \& Kautz, M. A. (1990). Color affects perceived odor intensity. Journal of Experimental Psychology, Human Perception and Performance, 16, 391- 397.

Zellner, D. A., Bartoli, A. M., \& Eckard, R. (1991). Influence of color on odor identification and liking ratings. American Journal of Psychology, 104, 547- 561.

Zurawicki, L. (2010). Neuromarketing: exploring the brain of the consumer. Berlin: Springer. 


\section{APPENDIX}

Formula (using R syntax):

preference $\sim$ Intercept + Age + Cultural belonging + Gender + Proffered color + Bottle color + Fragrance + I $1+$ I $2+$ I $3+$ I $4+$ I $5+$ I 6.

Parameter estimates

Table 4

Significant factors affecting consumer preference ratings (based on collected data)

\begin{tabular}{|c|c|c|c|c|c|}
\hline Factor & Estimate Std. & Error & $\mathrm{t}$ value & $\operatorname{Pr}(>|t|)$ & Signif \\
\hline (Intercept) & 7,479 & 0,35 & 21,083 & $<2 \mathrm{e}-16$ & $* * *$ \\
\hline Age $=$ Other & 0,44 & 0,32 & 1,40 & 0,16 & \\
\hline Cultural belonging $=\mathrm{CZE}$ & $-0,71$ & 0,29 & $-2,40$ & 0,02 & $*$ \\
\hline Gender $=$ male & 0,44 & 0,18 & 2,52 & 0,01 & $*$ \\
\hline Preffered colour $=$ Orange & 0,37 & 0,27 & 1,37 & 0,17 & \\
\hline Bottle colour = Purple & $-0,41$ & 0,23 & $-1,78$ & 0,08 & . \\
\hline Bottle colour $=$ Orange & $-0,46$ & 0,25 & $-1,81$ & 0,07 & . \\
\hline Bottle colour $=$ Yellow & $-0,74$ & 0,28 & $-2,65$ & 0,01 & $* *$ \\
\hline Fragrance = Lavender & $-1,18$ & 0,30 & $-3,96$ & 0,00 & $* * *$ \\
\hline Fragrance $=$ Orange & $-0,85$ & 0,27 & $-3,11$ & 0,00 & $* *$ \\
\hline Fragrance $=$ Grass & $-0,01$ & 0,23 & $-0,05$ & 0,96 & \\
\hline I1 Bottle colour = Orange $\&$ Fragrance $=$ Lavender & $-0,82$ & 0,43 & $-1,93$ & 0,05 & . \\
\hline I2 Bottle colour = Yellow \& Fragrance = Lavender & $-1,13$ & 0,44 & $-2,59$ & 0,01 & $* *$ \\
\hline I3 Bottle colour = Yellow \& Fragrance = Grass & 0,70 & 0,46 & 1,54 & 0,12 & \\
\hline I4 Gender $=$ male $\&$ Fragrance $=$ Orange & 0,52 & 0,35 & 1,48 & 0,14 & \\
\hline I5 Abroad = TRUE \& Fragrance = Orange or Lavender & $-0,65$ & 0,37 & $-1,74$ & 0,08 & . \\
\hline I6 Abroad = TRUE \& Green & $-0,71$ & 0,43 & $-1,66$ & 0,10 & \\
\hline
\end{tabular}

